\title{
IOs and Climate Change: Toward Global Eco-Social Policy
}

\author{
Silvana Lakeman
}

\section{INTRODUCTION}

The introduction to this book stated that International Organizations (IOs) "provide forums for exchange, guide and supervise international treaties, which states sign and adhere to," as well as "direct, finance and implement projects which affect people's lives" (see Niemann et al. in this volume). This is undoubtedly the case for the plethora of IOs engaging with climate change as a cross-cutting concern. Although climate change has perhaps only taken off as a clear global problem in the last 50 years (and social policy framings of the issue even later), it is evident that we now live in an age where "self-sufficiency in social policy is no longer a realistic option" (George and Wilding 2002, 187).

Environmental changes and social policies are linked in several ways. On the one hand, climate change is a cause of social risk for individuals with specific vulnerabilities (health, social and others), and for populations

\author{
S. Lakeman $(\bowtie)$ \\ Bremen International Graduate School of Social Science (BIGSSS), \\ University of Bremen, Bremen, Germany \\ e-mail: lakeman@bigsss.uni-bremen.de \\ (C) The Author(s) 2021 \\ K. Martens et al. (eds.), International Organizations in Global \\ Social Governance, Global Dynamics of Social Policy, \\ https://doi.org/10.1007/978-3-030-65439-9_11
}

255 
based in regions already affected by the more damaging consequences of climate change (such as rising sea levels or desertification). On the other hand, the typical measures and policies undertaken to tackle social and environmental problems are to a significant degree contradictory to one another; while social policy advancements are usually linked to economic development and growth, protecting the environment is better achieved by zero or even degrowth (Buch-Hansen and Koch 2019; Koch 2020). Furthermore, in the discussion of social policy and climate change, challenges converge in relation to social inequality and injustice. Questions abound regarding who is responsible for climate change and associated inequalities, especially as those countries and people causing the problem are typically the least affected. At the same time, global solidarity with respect to compensation for social problems related to climate change is of concern. This chapter discusses the role of international organizations in shaping global social policies in the field of climate change, also known as eco-social policies more broadly, and studies IOs in their function as forums for exchange and potential facilitators of international treaties, as laid out in the introduction to this volume.

This chapter proceeds in three steps. It first briefly highlights the temporal shift in discourse on climate change and the subsequent expansion of IOs engaging with the issue as a global social policy concern. For a long time, climate change was conceptualized in a narrow manner; however, in the twenty-first century context it is understood as an underlying issue for global social policy writ large, especially as it relates to the global concept of sustainable development. As outlined in a second section, this has led to a wide variety of IOs from various policy fields engaging with climate change as a determinant of social well-being and as an issue to be addressed through social policies, with rapid historical developments in this area challenging the traditional roles and mandates of IOs. To illustrate this point, a third section explores the position of IOs in relation to climate insurance as a global social policy tool. This chapter argues that IOs occupy an important space as conveners and for exerting influence-particularly 'soft' governance-when it comes to social policy dimensions of climate change, even if many IOs are not yet explicitly framing their work in such terms. A shift in global discourse on climate change-which has both given rise to the creation of IOs and been directly influenced by IO behavior-is illustrative of this point. 


\section{Shifting Discourse and Expanding IO Engagement}

In the field of climate change, there are numerous IOs exerting soft governance, opening spaces for discussion, and dealing with the issue as a cross-cutting concern for social policy. Certain IOs have clearly demarcated authority on climate change, such as the United Nations Framework Convention on Climate Change (UNFCCC) and the Intergovernmental Panel on Climate Change (IPCC). At the same time, a wider population of IOs with diverse mandates and functions-especially those in the United Nations (UN) family_now see climate change as an omnipresent threat, understanding it as an intersecting issue that needs to be addressed if original mandates are to be responsibly fulfilled.

From a historical perspective, the global discourse on climate change has undergone considerable transformation, of which IOs have been part and parcel. In the post-World War II context, major IOs addressed environmental change under the auspices of environmental conservation or climate science. In 1948, the UN established the International Union for the Protection of Nature and Human Resources (now the International Union Conservation of Nature and Human Resources, or IUCN) for environmental conservation, and in 1951 the World Meteorological Organization (WMO) to focus on climatic change. However, it was not until the 1960s and 1970s that a broader understanding of the global consequences of environmental degradation took hold in the international community, with climate change identified as a clear problem arising from industrialization in the Global North (Clapp and Dauvergne 2005, 48-82). This conceptualization was central to the UN's first global Conference on the Human Environment in Stockholm in 1972, which sparked the creation of the United Nations Environment Programme (UNEP) (Brisman 2011, 1039-1040). Given the rhetoric at the time, UNEP was mandated to contribute toward the development and implementation of policies which strike a balance between economic development and overcoming environmental degradation (Clapp and Dauvergne 2005, 57-58).

Further developments and events in the 1970s cemented both the recognition of climate change as a global issue, and the importance of IOs as collaborators and conveners in this domain. These included WMO's first international assessment of the state of the ozone layer in 1976, which was associated with growing global health concerns and triggered a range of studies over the following decades between WMO and UNEP (Social 
Learning Group 2001, 13), and the watershed World Climate Conference in 1979, which was a collaborative effort between WMO, the United Nations Educational, Scientific and Cultural Organization (UNESCO), the Food and Agriculture Organization of the United Nations (FAO), the World Health Organization (WHO), UNEP, the International Council for Science (ICSU), and other partners (Zillman 2009). The World Climate Conference resulted in WMO and UNEP together establishing the IPCC-now one of the most trusted sources for scientific consensus on climate change. Subsequent watershed successes for global climate change policy, especially the Montreal Protocol, were at least in part due to the involvement of IOs in assisting and including developing countries in the discussion on the environment, especially via the Multilateral Fund for the Implementation of the Montreal Protocol, which is managed by an Executive Committee comprising UNEP, the United Nations Development Programme (UNDP), the United Nations Industrial Development Organization (UNIDO), and the World Bank (Luken and Grof 2006).

In the 1980s, seeds were sown for current IO discourse and partnership on climate change with a focus on sustainable development. In 1980, IUCN partnered with UNEP, the World Wildlife Fund (WWF), FAO, and UNESCO (IUCN et al. 1980) to create the "World conservation strategy: living resource conservation for sustainable development." Although sustainability in that report focused more on the environment itself than (economic) development, by 1984, the UN General Assembly had established the World Commission on Environment and Development (WCED) (Clapp and Dauvergne 2005, 59-60). Providing a new definition for economic development with the environment at its core, the Brundtland Commission's 1987 report “Our Common Future" proposed a global development and environment strategy designed to be acceptable to all, popularizing the mainstream term 'sustainable development' as we know it today-development that "meets the needs of the present without compromising the ability of future generations to meet their own needs" (World Commission on Environment and Development 1987).

Following this report, multiple keystone conferences took place which have ultimately shaped current discourse on social policy and climate change. In 1990, a second World Climate Conference took place, and while its predecessor had led to the creation of the IPCC, the second presented the IPCC's first assessment report, which highlighted the risks of global climate change (IPCC and Houghton 1990). This event, coupled with the UN Conference on the Environment and Development 
(UNCED) in 1992 in Rio de Janeiro (the Earth Summit), led to the establishment of the UNFCCC. The UNFCCC would go on to dominate global discourse and act as the primary convening body for states looking to address climate change (Kuyper et al. 2018), as well as to play a direct role in the exploration of how to address some of the social consequences of climate change via social policy. More importantly, the Earth Summit cemented the notion of sustainable development as a vector for social policy, combined with the promotion of environmental protection (Clapp and Dauvergne 2005, 64).

Discursive focus on sustainable development dominated at the turn of the twenty-first century, as all UN Member States and a variety of associated IOs committed to eight Millennium Development Goals (MDGs) measured by targets in a variety of social issue areas. Although only the seventh goal explicitly relates to climate change ("to ensure environmental sustainability"), the 17 Sustainable Development Goals (SDGs) as a whole are considered far more interdependent, bringing together socioeconomic, political, and environmental sectors (Nilsson et al. 2016). Climate change and social policies both belong to the objectives to be achieved through the collective action model of the SDGs, and following decades of incremental developments, IOs now view climate change as a social policy concern. IOs which may not have originally or directly addressed climate change now do so anyway, with a common set of terms comprising the new discourse on IO involvement in this area; this notably includes the identification of vulnerable groups in the context of climate change and enhancing global resilience via mitigation, disaster risk reduction, and adaptation.

\section{Interconnected Policy and Action at the IO Level}

Following on from these developments, global social governance as the intersecting field of climate change and social policy (or eco-social policy) has evolved from a body of core IOs working on climate change and the environment (such as IUCN, UNEP, WMO, the IPCC, and the UNFCCC) to a wide variety of IOs with diverse mandates in the fields of migration, urbanization and population dynamics, livelihoods, health, WASH (water, sanitation, and hygiene), and poverty reduction, to name but a few. Nowadays, many UN specialized agencies, the World Bank, regional IOs, and the OECD may be considered global eco-social policy actors since they recognize climate change either as a direct or 
compounding issue for global social policy and integrate it into their work portfolios. In this section, a 'chain of connection' between climate change and various social policy areas is outlined as visible in the activities of major IOs; the starting and reference point being climate-change-induced migration.

Climate change has been recognized as early as the 1990s (including by the IPCC) as not only directly contributing toward migration and displacement (Martin 2010,397), but also as a contributing factor in major conflicts where migration and displacement are an outcome (PerchNielsen et al. 2008). Climate change is therefore of major concern for well-established and authoritative IOs in this area, such as the International Organization for Migration (IOM) and the United Nations High Commissioner for Refugees (UNHCR). In recent decades, IOM and UNHCR have lobbied for the inclusion of language that recognizes the link between climate change and human mobility in policy, including: the Hyogo Framework for Action and its successor, the Sendai Framework for Disaster Risk Reduction (UNDRR 2019); the state-led Nansen Initiative and its successor, the Platform on Disaster Displacement (McAdam 2016); and the UNFCCC Task Force on Displacement, established following the UNFCCC's twenty-first Conference of the Parties (COP21) meeting in Paris in 2015 "to develop recommendations to avert, minimize and address displacement in the context of the adverse effects of climate change" (UNFCCC 2020b). More recently, these agencies have also played a direct role in the formation and early implementation of the nonbinding Global Compact for Safe, Orderly and Regular Migration (GCM) and the Global Compact on Refugees (GCR), which include direct recognition of the impacts of climate change on global human mobility (UNHCR 2020; UNHCR and IOM 2019; United Nations 2019).

Such increased movements of people due to environmental stress and disaster may place strain on several other intersecting social policy areas. Climate-related factors such as increased drought and flooding speed up the process of urbanization, as community centers shift from rural to urban spaces. This in turn affects livelihoods, as people shift from agrarian practices in search of new types of work in urban centers. Although such shifts may represent opportunity, they can also equate to exacerbated societal inequality if poorly managed. Several IOs are working to address climate change in this context. The United Nations Population Fund (UNFPA), the International Institute for Environment and Development (IIED), and the United Nations Human Settlements Programme 
(UN-Habitat) regularly partner in a research and advisory capacity, for example, to support the implementation of the New Urban Agenda (NUA), which was adopted in 2016 (UN Habitat 2020; UNFPA 2020b). Likewise, the World Food Programme (WFP) has placed an emphasis on the need for sustainable livelihoods and ecosystems, as "every new drought or flood further depletes people's assets, trapping them in a spiral of diminishing resilience and environmental misery" (World Food Programme $2020 \mathrm{~b}$ ). This has also resulted in climate change having ultimately contributed to WFP's overwhelming spending on emergency and recovery operations following climate-related disasters in recent years (World Food Programme 2020a). Further at the heart of addressing threats to livelihoods, IOs exert influence via policy recommendations, as the International Labour Organization (ILO) has done in relation to promoting the use of social protection schemes to tackle unemployment in industries where activity must necessarily be reduced or phased out in the face of climate change, such as forestry and fossil fuel industries (Montt et al. 2018, 27). Meanwhile, other IOs have worked directly with local authorities to introduce schemes for improving livelihood opportunities for vulnerable groups. One example of this has been the introduction of hydroponic farming in flood prone areas as part of the trend toward community-based adaptation projects; in Bangladesh, pilot farming projects have been supported by UNDP (UNDP 2019), and farms for Bangladeshi returnee migrants have been supported by IOM alongside national authorities as part of a sustainable economic reintegration project (IOM 2018).

Shifting dynamics among populations and means of work in turn place a strain on urban capacities and housing as more people inhabit smaller spaces and strain existing services. UN-Habitat finds itself working at the intersection of these concerns, as it seeks to address bottle-neck issues affecting resilience and risk reduction, sustainable cities, and human mobility issues, among others (UN-Habitat 2020). Similarly, UNFPA has worked on hazard mapping in populated areas for climate change adaptation policy (POPClimate 2020), and has promoted policy practices for sustainable development and planning that set those most vulnerable to climate change on the path to a better life without contributing further to emissions and worsening climate change (UNFPA 2020a). Population shifts and ensuing challenges are in turn of direct concern for the domains of WASH, as well as health more generally, as they place societies at greater risk for a range of health implications often directly attributable to climate change, such as increased heat stress (Harlan et al. 2006), the spread of 
infectious disease such as malaria and cholera, malnutrition, and lack of access to clean drinking water, not to mention the mental health risks associated with livelihood and migratory-related stress. WHO has to that end emphasized the need for a continual flow of information between science, research, and policy, with their language emphasizing sustainability and measures for adaptation and reducing vulnerability (McMichael et al. 2003). Although a core authority on health, WHO is not the only viable IO considering health in the context of climate change and exerting soft governance-the aforementioned Sendai Framework for Disaster Risk Reduction 2015-2030 has included health as a key outcome, with actions for public health outlined and prioritized by the United Nations Office for Disaster Risk Reduction (UNDRR), WHO, and others in the UN system (Aitsi-Selmi and Murray 2016). Health is also a key area under the UNFCCC's Nairobi Work Programme, established at COPll to convene "knowledge for action" for climate adaptation and resilience (UNFCCC 2020c), and WHO was contributing to health aspects of the Inter-Agency Committee on the Climate Agenda (IACCA) — in partnership with WMO, UNESCO, the International Olympic Committee (IOC), FAO, and ICSU_as early as 1998 (WMO et al. 1998).

In considering how interconnected such issues are, other IOs are in turn forced to address climate change in their policy work regarding vulnerable groups — such as women and children-who have been identified as disproportionately affected, particularly in areas such as health and livelihoods (Huyer et al. 2015, 4; Preet et al. 2010, 5). IOs such as UN Women (created in 2010) are addressing climate change and exerting soft power in this area by facilitating platforms for the participation of women in decision-making, with the goal to achieve more gender-sensitive policy outcomes. This is clear in their disaster risk reduction work, where they have been active in supporting disaster management bodies at the national level in countries such as Nepal, Myanmar, Vanuatu, Bangladesh, and Kenya, and at the regional and global level alongside IO partners such as UNDRR as well as Member States to develop 'gender responsive' implementation plans and programs for the Sendai Framework (UN Women 2020 b). More broadly, UN Women also focuses on economic empowerment for women within the UN's Sustainable Development Agenda, specifically seeking combatant or adaptive solutions to climate change (UN Women 2020c). A directly observable outcome of this is the IO's facilitation of training seminars for those looking to diversify their livelihoods as part of adaptation measures (UN Women 2020a). Similarly, the United 
Nations Children's Fund (UNICEF) has restructured its climate change policy around children as central actors, visible through their facilitation of projects in Bolivia and Papua New Guinea for youth leadership in water resources management and disaster response plans for schools, and more broadly in their provision of a platform for children and young people at United Nations events (UNICEF 2020). As part of efforts to enhance resilience in the face of climatic and environmental shocks, UNICEF and FAO have for many years engaged in and evaluated the potential for social policy schemes such as cash transfer programs to enhance the resilience of vulnerable groups in the face of climate change (Davis et al. 2016; FAO 2018; Lawlor et al. 2015).

The notion of global social governance as developed in this chapter suggests an increasing contextualization of global social policies in relation to the global threat of climate change. In other words, in the description of the causes or determinants of social problems and challenges, climate change takes an increasingly prominent role. Furthermore, as climate change plays out in multiple ways for the well-being and livelihoods of people, IOs that previously had clearly assigned mandates, roles, and responsibilities are crossing (social) policy fields in response to the global threat of climate change. In this sense, global social policy is increasingly evolving into global eco-social policy, with actors forming interconnected governance structures that merge social policy with environmental policy agendas and prescriptions. To illustrate this argument, the following section will describe climate change/risk insurance as one potential option for merging traditional social policy tools with climate change policies, highlighting the activity of and between various IOs in this area.

\section{'Climate Risk Insurance’ for Global Eco-Social Policy? A Case Study}

Climate change is bringing IOs and other relevant partners together in new, exciting, and-as this section will show-sometimes questionable ways. Climate risk insurance, or climate (change) insurance, is both representative of emerging social policy solutions and an opportunity to reflect upon the extent to which IOs are moving beyond the realm of their 'regular' work in research, advising, and assessment. Climate insurance is an example of the economization of climate change and is rather unique in its ability to bring together a wide range of actors from the public and private 
spheres. The proliferation of work in this area is not so surprising when considering that economic language and doctrines satisfy the liberal governance model, especially where action at the national level may be deemed insufficient, thus opening space for IOs to exert soft power (Palmujoki 2010). Extreme weather events have been typically financed by a mixture of public and international disaster relief, however, as climate change increases the intensity and frequency of both sudden and slow-onset climatic events, the international community-including IOs-have been forced to question existing tools for tackling the economic consequences of climate change (Miller and Swann 2016,81). As a result, IOs, governments, and private enterprises are all considering the potential for insurance as a tool for both adapting to and addressing potential losses and damages due to climate change. From the perspective of IOs concerned with the more wide-reaching effects of climate change on the future of sustainable development, the potential of climate insurance is arguably even more important; according to Kofi Annan, former United Nations Secretary General, climate insurance "may hold answers for some of the more obstinate problems faced by the poor and the vulnerable" (Hellmuth et al. 2009, iii).

There are two major points of consensus stemming from this field: First, that dependent on its use, climate insurance represents an option or tool for combatting the more drastic effects of climate change and for adapting to future risks and losses (International Finance Corporation 2016, 1; Montt et al. 2018, 12); and second, climate insurance must be planned, funded, and carried out by a range of actors from the public, private, and international spheres. This is in recognition of the fact that better coordination of shared approaches may result in better climate adaptation tools (Wilby et al. 2009, 1197). In other words, polycentric governance is a requirement, and this definitively requires the involvement of IOs (Kreft et al. 2017, 24; Miller and Swann 2016, 70). Although the pervasive nature of climate change as regards wider social policy was illustrated in the last section, climate change insurance as a potential solution to many of the ills caused by climate change deserves stand-alone consideration. This is due to its ability to both bring together a unique array of actors from public, private, and international sectors, and present unique challenges that are equal parts practical, theoretical, and ethical.

The last decade has seen a proliferation of work in the field of climate risk insurance and climate finance more broadly, with IOs playing no small role in both establishing the concept and paving the way for future work 
in this area. The UNFCCC is considered the leading organization in this regard. As part of 'Cancun Agreements' at COP16 in 2010, the Green Climate Fund and 'fast-start finance' were established, where developed countries pledged to mobilize funding which would go through IOs in the hopes of reaching populations most vulnerable to climate change (UNFCCC 2020a). The Green Climate Fund (of which the World Bank is trustee, although the Fund is subject to the COP) aims to tap into both public and private finances in order to bankroll projects in climate change mitigation and adaptation (Green Climate Fund 2020). By 2015, the Fund had obtained over US $\$ 10$ billion in pledges and had begun approving investments (Kreft et al. 2017,36), and despite a lack of new contributions from the United States, in the latest fundraising round (2019) developed countries pledged an additional US \$9.8 billion (Yeo 2019).

The Cancun Adaptation Framework (another result of COP16) also promoted "risk assessment and management as well as risk sharing and transfer mechanisms such as insurance at local, national, sub-regional and regional levels," and suggested the creation of a climate risk insurance facility "to address impacts associated with severe weather events" (Warner et al. 2013,39). Perhaps most consequential for current work in this area is the Warsaw International Mechanism for Loss and Damage (commonly referred to as the WIM), which was established in 2013 during UNFCCC climate negotiations to look into insurance scheme options that may address climate change problems (Spreng et al. 2016, 130). States party to the UNFCCC are fully aware of the potential of climate risk insurance, with some 38 countries (representative of over four billion people and "approximately half of the world's extreme poor") privy to the 2015 Paris Agreement including climate risk insurance approaches (or at least some mention of the issue) in their Nationally Determined Contributions (NDCs) (Kreft et al. 2017, 10). There is also a consensus at the international governance level that differentiation between developed and developing countries plays an important role for future work in this area, with the G7 calling for climate change insurance schemes (Spreng et al. 2016, $130)$ and the UNFCCC Article 3.1.1. explicitly recognizing "differentiated responsibilities and respective capabilities," with developed countries responsible for taking the lead "in combating climate change and the adverse effects thereof"' (United Nations 1992, 9).

The intensive work of the UNFCCC in this area is more easily understandable when considered in relation to the bigger UN Agenda on Sustainable Development, where climate insurance holds plenty of 
promise. Historically, those vulnerable to risks such as environmental disasters have typically financed their recovery by way of "savings and credit, informal kinship arrangements, government relief and international donor support" (Linnerooth-Bayer et al. 2019, 489). Insurance options may therefore relieve IOs from many of the associated costs of climate change, such as humanitarian aid. Multiple IOs have unsurprisingly begun investigative work, with the International Fund for Agricultural Development (IFAD) and WFP establishing a Weather Risk Management Facility in 2008 to test the feasibility of index-insurance (IFAD 2020). Nonetheless, the potential for climate insurance to pave the way for an increase in the rich-poor divide remains a concern, particularly given that climate change itself "raises awareness and willingness in populations to insure but threatens the affordability and availability of cover" (Lamond and Penning-Rowsell 2014, 2). This is something that IOs which are involved in developing policies and schemes, and for which fair and equitable sustainable development is a major reason for investing in insurance options, are concerned about. A potential issue may be increased engagement between the private sector and developed countries, at the expense of, or as a substitute for, continued official development assistance (ODA).

Not only is the prospect of reduced costs of interest for IOs, but wider work on climate insurance nominates IOs as middlemen for financing projects. For example, one study has proposed a regional financial mechanism funded by intergovernmental organizations (IGOs) and developed countries for tackling rising sea levels in Small Island Developing States based on the success of existing financial contributions to the African Risk Capacity (ARC), which has provided insurance to African countries affected by drought (Wenta et al. 2016). Similarly, the United Nations University (UNU) has outlined that IOs are well positioned to provide both technical and financial assistance, and occupy a unique position for facilitating regional and international dialogue on insurance options (Warner et al. 2013, 40). It is therefore in the interest of IOs that any mechanisms they fund be professionally researched; the Munich Climate Insurance Initiative (MCII) is an example of an arrangement for research on insurance options between Munich Re and UNU (Kreft et al. 2017). Other IOs that have in the past partnered to investigate the prospects of insurance for development include Oxfam America, UNDP, WFP, the International Research Institute for Climate and Society (IRI), and IFAD (Hellmuth et al. 2009). 
While it has been argued that State-backed schemes provide social benefits and protection measures for vulnerable populations that purely private enterprises 'struggle to emulate,' the inclusion of IOs with specific goals to improve the lives of target populations offers an opportunity to balance the scales against exploitation (Lamond and Penning-Rowsell $2014,5)$. Conversely, partnering with IOs under the auspices of sustainable development for climate change provides an access route for insurers who are keen to exhibit altruistic qualities, as the International Finance Corporation (2016, 1), a member of the World Bank Group, has argued. To date, partnerships between private or profit-driven insurers and IOs have resulted in hybrid schemes such as the Caribbean Catastrophe Risk Insurance Facility (CCRIF), a partnership where "World Bank instruments and donor funds are accessed by a private company owned and operated by its regional members to support its not-for-profit goals" (Warner et al. 2013, 30). Another example is WFP and Oxfam America's R4 Rural Resilience Initiative, which relies on donations from a range of other IOs, non-governmental organizations (NGOs), governments, and insurance firms interested in extending their humanitarian work to reach hundreds of thousands of farmers in Africa to improve "resource management through asset creation," provide insurance, allow for livelihoods diversification, micro crediting, and improvements in savings (World Food Programme and Oxfam America 2018). Whether or not such arrangements result in pushing the Sustainable Development Agenda and tackling social problems caused by climate change, or merely facilitate access to 'emerging markets' for foreign insurance companies (potentially limiting the ability of national governments to determine their own social protection measures) remains a critical and serious question.

\section{CONCLUSION}

This chapter has traced the development of global social governance as eco-social policy with a focus on the links between climate change and social policies. It has described the temporal shift within the global discourse on climate change with an emphasis on the roles of, and collaborations between, an increasing number of IOs. It has explored some interconnected issues of social and climate change policies and highlighted how many IOs are engaged in the field. In a third step, it was shown using the example of climate risk insurance how an insurance mechanism brings actors and efforts together within multi-actored and multi-level processes 
to facilitate tackling individual social shocks caused by climate change, as well as how such a tool may bundle the resources and capacities of IOs involved.

More specifically, this chapter has outlined advancements in discourse at the IO level on climate change and how this connects to global social policies. It has illustrated how a shift toward framing climate change in the context of sustainable development has led to a ballooning of IOs engaged in this area. The argument that IOs occupy an important space as conveners and for exerting influence-particularly 'soft' governance-when it comes to social policy and climate change, has been shown with the example of climate risk insurance.

This argument is, however, specific to the perspective on global ecosocial governance employed: Gough (2014) has, for example, considered green growth and how economic and social policies come together with reference to that perspective. Here, a lot of questions remain concerning the ability of IOs to counter the interests of powerful, economically oriented states or big business. Nonetheless, eco-social policies, the links between climate change and social policies, and the specific roles of IOs (and other actors) is still highly underexplored, and considering global social governance as global eco-social policy is a perspective in need of further consideration in the years and decades to come.

\section{REFERENCES}

Aitsi-Selmi, Amina, and Virginia Murray. 2016. "Protecting the Health and WellBeing of Populations from Disasters: Health and Health Care in The Sendai Framework for Disaster Risk Reduction 2015-2030." Prehospital and Disaster Medicine 31 (1): 74-78. 10.1017/S1049023X15005531.

Brisman, Avi 2011. "Stockholm Conference, 1972." In Encyclopedia of Global Justice, edited by Deen K. Chatterjee, 1039-1040. Dordrecht: Springer.

Buch-Hansen, Hubertus, and Max Koch. 2019. "Degrowth through Income and Wealth Caps?” Ecological Economics 160: 260-271.

Clapp, Jennifer, and Peter Dauvergne. 2005. Paths to a Green World: The Political Economy of the Global Environment. Cambridge, Mass.: The MIT Press.

Davis, Benjamin, Sudhanshu Handa, Nicola Hypher, Natalia Winder Rossi, Paul Winters, and Jennifer Yablonski, eds. 2016. From Evidence to Action: The Story of Cash Transfers and Impact Evaluation in Sub-Saharan Africa. Oxford: FAO, UNICEF and Oxford University Press.

FAO. 2018. FAO and Cash+. How to Maximise the Impacts of Cash Transfers. http://www.fao.org/3/I8739EN/i8739en.pdf. Accessed May 7, 2020. 
George, Vic, and Paul Wilding. 2002. Globalisation and Human Welfare. Basingstoke: Palgrave Macmillan.

Gough, Ian. 2014. "Climate Change, Social Policy, and Global Governance." In Transformations in Global and Regional Social Policies. edited by Alexandra Kaasch and Paul Stubbs, 108-133. Basingstoke: Palgrave Macmillan.

Green Climate Fund. 2020. Green Climate Fund. https://www.greenclimate. fund/. Accessed April 24, 2020.

Harlan, Sharon L., Anthony J. Brazel, Lela Prashad, William L. Stefanov, and Larissa Larsen. 2006. "Neighbourhood Microclimates and Vulnerability to Heat Stress." Social Science \& Medicine 63 (11): 2847-2863. https://doi. org/10.1016/j.soscimed.2006.07.030.

Hellmuth, Molly E., Daniel E. Osgood, Ulrich Hess, Anne Moorhead, and Haresh Bhojwani, eds. 2009. Index Insurance and Climate Risk: Prospects for Development and Disaster Management. Climate and Society No. 2. International Research Institute for Climate and Society (IRI). Columbia University, New York, USA.

Huyer, Sophie, Jennifer Twyman, Manon Koningstein, Jacqueline Ashby, and Sonja Vermeulen. 2015. Supporting Women Farmers in a Changing Climate: Five Policy Lessons. Policy Brief 10. CGIAR, CCAFS, Research Program on Climate Change, Agriculture and Food Security. https://cgspace.cgiar.org/ bitstream $/$ handle $/ 10568 / 68533 /$ CCAFS\%20 PB 10.pdf? sequence $=$ 2\&isAllowed=y. Accessed April 14, 2020.

IFAD. 2020. IFAD-WFP Weather Risk Management Facility. 2020. https:// www.ifad.org/en/wrmf. Accessed April 12, 2020.

International Finance Corporation. 2016. EMCompass, Fresh Ideas about Business in Emerging Markets, Note 13: Insurance Options for Addressing Climate Change. World Bank Group Open Knowledge Repository. https:// openknowledge.worldbank.org/handle/10986/30339.

Accessed April 7, 2020.

IOM. 2018. Bangladeshi Survivors of Andaman Sea Crisis Find New Livelihoods in Hydroponic Farming. https://reliefweb.int/report/bangladesh/ bangladeshi-survivors-andaman-sea-crisis-find-new-livelihoods-hydroponicfarming. Accessed April 11, 2020.

IPCC, and Sir John Theodore Houghton. 1990. IPCC First Assessment Report. Geneva: WMO.

IUCN, UNEP, WWF, FAO, and UNESCO. 1980. World Conservation Strategy: Living Resource Conservation for Sustainable Development. Gland, Switzerland: IUCN.

Koch, Max 2020. "The State in the Transformation to a Sustainable Postgrowth Economy.” Environmental Politics 29 (1): 1-19. https://doi.org/10.108 0/09644016.2019.1684738. 
Kreft, Soenke, Laura Schaefer, and Eike Behre. 2017. Climate Risk Insurance for Resilience: Assessing Countries' Implementation Plans. An Analysis in the Context of NDCs (Nationally Determined Contributions) and Policy Recommendations, Report 2017, No. 23. United Nations University.

Kuyper, Jonathan, Heike Schroeder, and Björn-Ola Linnér. 2018. "The Evolution of the UNFCCC." Annual Review of Environmental Resources 43: 343-368. https://doi.org/10.1146/annurev-environ-102017-030119.

Lamond, Jessica, and Edmund Penning-Rowsell. 2014. "The Robustness of Flood Insurance Regimes given Changing Risk Resulting from Climate Change.” Climate Risk Management 2: 1-10.

Lawlor, Kathleen, Sudhanshu Handa, David Seidenfeld, and Zambia Cash Transfer Evaluation Team. 2015. Cash Transfers and Climate-Resilient Development: Evidence from Zambia's Child Grant Programme. UNICEF. https://www. unicef-irc.org/publications/777-cash-transfers-and-climate-resilientdevelopment-evidence-from-zambias-child-grant.html. Accessed April 142020.

Linnerooth-Bayer, Joanne, Swenja Surminski, Laurens M. Bouwer, Ilan Noy, and Reinhard Mechler. 2019. "Insurance as a Response to Loss and Damage?'” In Loss and Damage from Climate Change, edited by Reinhard Mechler, Laurens M. Bouwer, Thomas Schinko, Swenja Surminski and JoAnne LinneroothBayer., 483-512. Cham: Springer.

Luken, Ralph, and Tamas Grof. 2006. “The Montreal Protocol's Multilateral Fund and Sustainable Development." Ecological Economics 56 (2): 241-255. 10.1016/j.ecolecon.2004.04.013.

Martin, Susan. 2010. "Climate Change, Migration, and Governance." Global Governance 16 (3): 397-414.

McAdam, Jane. 2016. "From the Nansen Initiative to the Platform on Disaster Displacement: Shaping International Approaches to Climate Change, Disasters and Displacement." University of New South Wales Law Journal 39 (4): 1518-1546.

McMichael, A.J., D.H. Campbell-Lendrum, C.F. Corvalán, K.L. Ebi, A. Githeko, J.D. Scheraga, and A. Woodward, eds. 2003. Climate Change and Human Health - Risks and Responses. Geneva: World Health Organization.

Miller, Alan S, and Stacy A Swann. 2016. "Climate Change and the Financial Sector: A Time of Risk and Opportunity." Georgetown Environmental Law Review 29 (1): 69-110.

Montt, Guillermo, Federico Fraga, and Marek Harsdorff. 2018. The Future of Work in a Changing Natural Environment: Climate Change, Degradation and Sustainability. International Labour Organization. https://www.greengrowthknowledge.org/sites/default/files/downloads/resource/The_future_of_ work_in_a_changing_natural_environment_ILO.pdf. Accessed April 13, 2020.

Nilsson, Mans, Dave Griggs, and Martin Visbeck. 2016. "Policy: Map the Interactions between Sustainable Development Goals.” Nature 534 (321). 
https://www.nature.com/news/policy-map-the-interactions-betweensustainable-development-goals-1.20075. Accessed April 19, 2020.

Palmujoki, Eero. 2010. "International Organisations and the Rhetoric of Climate Change." Journal of the Indian Ocean Region 6 (2): 189-205. https://doi. org/10.1080/19480881.2010.536664.

Perch-Nielsen, Sabine L, Michele B. Bättig, and Dieter Imboden. 2008. "Exploring the Link between Climate Change and Migration." Climatic Change 91: 375-393. https://doi.org/10.1007/s10584-008-9416-y.

POPClimate. 2020. Demographic Explorer for Climate Adaptation (DECA). http://www.popclimate.net/DECA. Accessed April 292020.

Preet, Raman, Maria Nilsson, Barbara Schumann, and Birgitta Evengård. 2010. "The Gender Perspective in Climate Change and Global Health." Global Health Action 3 (1). Article 5720. https://doi.org/10.3402/gha.v3i0.5720.

Social Learning Group 2001. Learning to Manage Global Environmental Risks, Vol. 2: A Functional Analysis of Social Responses to Climate Change, Ozone Depletion, and Acid Rain. Boston: MIT Press.

Spreng, Connor P., Benjamin K. Sovacool, and Daniel Spreng. 2016. "All Hands on Deck: Polycentric Governance for Climate Change Insurance." Climatic Change 139: 129-140. https://doi.org/10.1007/s10584-016-1777-z.

UN Habitat. 2020. Partners: Partnerships towards Sustainable Urbanization https://unhabitat.org/partners. Accessed April 24, 2020.

UN Women. 2020a. Strengthening Women's Livelihoods and Resilience to Disasters and Climate Change in Viet Nam. https://www.unwomen.org/en/ news/stories/2020/1/feature\%2D\%2Dwomens-livelihoods-and-resilience-inviet-nam. Accessed May 5, 2020.

UN Women. 2020b. UN Women, Disaster Risk Reduction. https://www. unwomen.org/en/what-we-do/humanitarian-action/disaster-risk-reduction. Accessed May 6, 2020.

UN Women. 2020c. UN Women, Sustainable Development and Climate Change. https://www.unwomen.org/en/what-we-do/economic-empowerment/ sustainable-development-and-climate-change. Accessed May 17, 2020.

UNDP. 2019. Hydroponic Farming Being Adopted in Coastal Region. https:// www.bd.undp.org/content/bangladesh/en/home/presscenter/pressreleases $/ 2019 / 10 / 16 /$ hydroponic-farming-being-adopted-in-coastal-region. html. Accessed May 25, 2020.

UNDRR. 2019. Sendai Framework for Disaster Risk Reduction. https://www. unisdr.org/we/coordinate/sendai-framework. Accessed May 4, 2020.

UNFCCC. 2020a. Cancun Agreements. https://unfccc.int/process/conferences/pastconferences/cancun-climate-change-conference-november-2010/ statements-and-resources/Agreements.Accessed May 17, 2020

UNFCCC. 2020b. COP24 Side Event: Recommendations of the Task Force on Displacement. https://unfccc.int/process-and-meetings/bodies/constituted- 
bodies/executive-committee-of-the-warsaw-international-mechanism-for-lossand-damage-wim-excom/workshops-meetings/cop24-side-eventrecommendations-of-the-task-force-on-displacement. Accessed 5 May, 2020.

UNFCCC. 2020c. Health. https://www4.unfccc.int/sites/NWPStaging/ Pages/Health-page.aspx. Accessed May 15, 2020.

UNFPA. 2020a. Climate Change. https://www.unfpa.org/climate-change. Accessed May 7, 2020.

UNFPA. 2020b. Urbanization. https://www.unfpa.org/urbanization. Accessed April 23, 2020.

UN-Habitat. 2020. Climate Change. https://unhabitat.org/topic/climatechange. Accessed April 16, 2020.

UNHCR. 2020. The Global Compact on Refugees. https://www.unhcr.org/theglobal-compact-on-refugees.html. Accessed April 15, 2020.

UNHCR, and IOM. 2019. Joint IOM-UNHCR Letter on Global Compact for Safe, Regular and Orderly Migration. IASC. https://interagencystandingcommittee.org/principals/documents-public/joint-iom-unhcr-letter-globalcompact-safe-regular-and-orderly-migration. Accessed May 1, 2020.

UNICEF. 2020. Environment and Climate Change. https://www.unicef.org/ environment-and-climate-change. Accessed May 4, 2020.

United Nations. 1992. United Nations Framework Convention on Climate Change. UNFCCC. https://unfccc.int/files/essential_background/ background_publications_htmlpdf/application/pdf/conveng.pdf. Accessed May 7, 2020.

United Nations. 2019. Global Compact for Migration. https://refugeesmigrants. un.org/migration-compact. Accessed April 14, 2020.

Warner, Koko, Kristina Yuzva, Michael Zissener, Susan Gille, Janina Voss, and Solveig Wanczeck. 2013. "Innovative Solutions for Climate Change: How to Integrate Climate Risk Insurance into a Comprehensive Climate Risk Management Approach. Report No. 12." United Nations University Institute for Environment and Human Security (UNU-EHS). https://i.unu.edu/ media/ehs.unu.edu/news/3796/11484.pdf. Accessed May 8, 2020.

Wenta, Joseph, Jeffrey McGee, and Liam Phelan. 2016. "Can a Regional Insurance Mechanism Enhance Resilience to Slow Onset Impacts of Climate Change?” The University of Tasmania Law Review 35 (2): 23-57.

Wilby, R.L., J. Troni, Y Biot, L. Tedd, B. C. Hewitson, D.M Smith, and R.T. Sutton. 2009. "Review: A Review of Climate Risk Information for Adaptation and Development Planning." International Journal of Climatology 29: 1193-1215. https://doi.org/10.1002/joc.1839.

WMO, WHO, UNESCO, UNEP, IOC, FAO, and ICSU. 1998. Inter-Agency Committee on the Climate Agenda: Report of the Second Session of the InterAgency Committee on the Climate Agenda (IACCA) (Geneva, 16-17 April 1998). WMO. https://library.wmo.int/doc_num.php?explnum_id=9706. Accessed May 5, 2020. 
World Commission on Environment and Development. 1987. Our Common Future. Oxford: Oxford University Press.

World Food Programme. 2020a. Climate Action. https://www.wfp.org/climateaction. Accessed May 5, 2020.

World Food Programme. 2020b. Sustainable Livelihoods and Ecosystems. https://www.wfp.org/sustainable-livelihoods-and-ecosystems. Accessed April 16, 2020.

World Food Programme, and Oxfam America. 2018. R4 Rural Resilience Initiative: Building Resilience to Climate Change for Long-Term Food Security and Livelihoods Improvement. WFP. https://docs.wfp.org/api/documents/ b9a3d33bd9974e5aaf01bl la3e3da410/download/. Accessed May 3, 2020.

Yeo, Sophie. 2019. Green Climate Fund attracts record US\$9.8 billion for developing nations. Nature. https://www.nature.com/articles/d41586-01903330-9. Accessed May 24, 2020.

Zillman, John W. 2009. A History of Climate Activities. WMO Bulletin 58(3) July 2009. https://public.wmo.int/en/bulletin/history-climate-activities. Accessed April 20, 2020.

Open Access This chapter is licensed under the terms of the Creative Commons Attribution 4.0 International License (http://creativecommons.org/licenses/ by $/ 4.0 /$ ), which permits use, sharing, adaptation, distribution and reproduction in any medium or format, as long as you give appropriate credit to the original author(s) and the source, provide a link to the Creative Commons licence and indicate if changes were made.

The images or other third party material in this chapter are included in the chapter's Creative Commons licence, unless indicated otherwise in a credit line to the material. If material is not included in the chapter's Creative Commons licence and your intended use is not permitted by statutory regulation or exceeds the permitted use, you will need to obtain permission directly from the copyright holder.

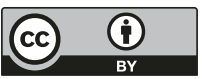

